\title{
The effect of phosphatidylserine-containing omega-3 fatty acids on memory abilities in subjects with subjective memory complaints: a pilot study
}

\author{
This article was published in the following Dove Press journal: \\ Clinical Interventions in Aging \\ 29 October 2010 \\ Number of times this article has been viewed
}

\author{
Yael Richter' \\ Yael Herzog' \\ Tzafra Cohen' \\ Yael Steinhart ${ }^{2}$ \\ 'Enzymotec LTD, Migdal-HaEmeq, \\ Israel; ${ }^{2}$ Department of Marketing, \\ Haifa Graduate School of \\ Management, University of Haifa, \\ Israel
}

Correspondence:Yael Steinhart Department of Marketing, Haifa Graduate School of Management, University of Haifa, Israel

Tel +972 (0) 48249582

Fax $+972(0) 48249194$

Email ysteinhart@gsb.haifa.ac.il
Objective: To evaluate for the first time the efficacy of safe-sourced phosphatidylserinecontaining omega-3 long chain polyunsaturated fatty acid (PS-omega-3) in improving memory abilities.

Methods: PS-omega-3 was administered daily for 6 weeks to eight elderly volunteers with subjective memory complaints. The Cognitive Drug Research test battery was used to assess the effect on their cognitive abilities.

Results: PS-omega-3 supplementation resulted in $42 \%$ increase in the ability to recall words in the delayed condition.

Conclusion: PS-omega-3 may have a favorable effect on memory in subjects with subjective memory complaints. PS-omega-3 may serve as a safe alternative to phosphatidylserine extracted from bovine cortex.

Keywords: cognitive, memory, omega-3, phosphatidylserine

\section{Introduction}

Declines in cognitive functions, such as memory, are characteristic of normal aging. ${ }^{1,2}$ Several age-related neurochemical changes have been associated with biochemical, structural, and functional neuronal membrane alterations, such as changes in the composition and/or content of lipids, leading to a loss in membrane fluidity. ${ }^{3}$ There is a growing body of scientific findings supporting the crucial role of phosphatidylserine (PS) in improving and reversing this neurochemical damage caused by age and/or disease. ${ }^{4}$

Indeed, PS has been shown to play a key role in the functioning of neuron membranes, such as signal transduction, secretory vesicle release, cell-to-cell communication, and cell growth regulation. ${ }^{5}$

Early observations associated the administration of PS extracted from bovine cortex (BC-PS) with positive effect on brain function. Supplementation of BC-PS (300 mg $\mathrm{PS} / \mathrm{d}$ ) to subjects with age-associated memory impairment (AAMI) resulted in improved performance in tests related to attention, learning, and memory tasks of daily life. Interestingly, some of the tested parameters improved even following short-term administration (3 weeks). ${ }^{6}$ Providing BC-PS (300 mg PS/d) to geriatric patients significantly enhanced behavioral and cognitive parameters. ${ }^{7}$ Importantly, BC-PS supplementation to patients with Alzheimer's disease had positive effect on their cognitive performance. ${ }^{8,9}$ The abovementioned clinical evidence is supported by numerous preclinical studies in which supplementation with BC-PS has been shown to attenuate neuronal effects of 
aging and restoring normal memory on a variety of tasks. In these studies, BC-PS has been shown to affect multiple neurochemical systems, neuronal membranes, ${ }^{10}$ cell metabolism, ${ }^{4}$ and neurotransmitter systems including acetylcholine, ${ }^{11}$ norepinephrine, ${ }^{12}$ serotonin, and dopamine. ${ }^{13}$

Due to safety concerns of the risk for prion contamination in BC-PS, soybean-derived PS (SB-PS) was established as a safe alternative. SB-PS, however, differs considerably from BC-PS, mainly in the absence of docosahexaenoic acid (DHA), which is the predominant omega-3 long chain polyunsaturated fatty acid (LC-PUFA) in the mammalian central nervous system. Indeed, inconclusive results have been obtained following interventions of SB-PS to AAMI subjects. ${ }^{14,15}$

In the present exploratory open trial, we evaluated for the first time the efficacy of a safe-sourced PS with omega-3 LC-PUFA attached to its backbone (PS-omega-3), in treating subjective memory complaints following short-term administration.

\section{Methods}

\section{Subjects}

A total of eight men and women volunteers aged $\geq 60$ years with subjective memory complaints were recruited through an advertisement in the local newspaper in Haifa, Israel. Subjects were excluded from the study if used coexisting medication or supplement, which influences cognitive performance, had history of hypersensitivity or allergy to soy or fish, or were unable to perform the cognitive tests in Hebrew. Informed consent was obtained from all subjects. The study was approved by the Ethics Committee of the University of Haifa, Israel.

\section{Study design and supplement}

The study was designed as a single-center, open-label study. Duration of treatment was 6 weeks. All participants received three PS-omega-3 capsules (Sharp-PS ${ }^{\circledR}$ GOLD; Enzymotec LTD, Migdal HaEmeq, Israel) per day. The daily dosage contained $300 \mathrm{mg}$ PS and $37.5 \mathrm{mg}$ Eicosapentaenoic acid + DHA. For treatment adherence monitoring, the treatment packs were returned at the end of the study, and compliance was calculated based on number of capsules remaining.

\section{Outcome measures}

\section{Cognitive outcome measures}

Subjects were evaluated for their cognitive performance at baseline and at study termination ( 6 weeks) using the Cognitive Drug Research (CDR) computerized assessment battery. ${ }^{16}$ Participants were engaged in a training session for a week before baseline measures and treatment initiation, in order to generate a common level of familiarity with the task. On each testing session, parallel but equivalent forms of the tests were presented.

The CDR battery includes nine separate tasks and five composite factors calculated from the results on the single tasks. "Power of attention" factor is derived by combining the reaction times of the three attentional tasks (simple and choice reaction time and digit vigilance). "Continuity of attention" factor is derived by calculating the combined percentage accuracy across the choice reaction time and digit vigilance tasks. "Quality of working memory" factor is derived by combining the percentage accuracy scores from the two working memory tests (spatial and numeric working memory). "Quality of episodic secondary memory" factor is derived by combining the composite score working memory with the percentage accuracy scores from all secondary memory tests (recognition and recall tests). "Speed of memory" factor is derived by combining the reaction times of the four memory tasks (delayed picture and word recognition, numeric working memory, and spatial memory).

\section{Subjective mood measure}

Mood was assessed by the Bond-Lader Visual Analog Scales of Mood and Alertness (computerized version of the test), consisting of 16 analog scales which are combined, as recommended by Bond and Lader ${ }^{18}$ to form three assessments: alertness, contentment, and calmness.

\section{Statistical methods}

The Wilcoxon signed-rank test was used to test the improvement from baseline to follow-up visit at 6 weeks. This nonparametric test was selected due to the small numbers and the deviation from normality of the cognitive measures. $P<0.05$ was considered significant, without correction for multiple comparisons.

Analysis was done using SPSS software (version 17; SPSS Inc, Chicago, IL).

\section{Results}

A total of eight elderly volunteers (three men and five women) with subjective memory complaints were enrolled in the study. The mean age of subjects was 69.3 years (standard deviation 3.2). The treatment was well tolerated, and no adverse events were reported. All subjects completed the study and were, therefore, eligible for statistical analyses.

\section{CDR outcome measures}

Task outcomes in the order they were undertaken, and performance data are presented in Table 1. Following 
Table I Effect of PS-omega-3 on individual task outcome measures and cognitive factor scores from the CDR battery. Mean baseline and study termination scores are presented (with standard errors of the mean)

\begin{tabular}{|c|c|c|c|}
\hline CDR measure & Baseline & Six weeks & $\mathbf{P}$ \\
\hline \multicolumn{4}{|l|}{ Individual task } \\
\hline Immediate word recall (\% accuracy) & $36.67 \pm 4.36$ & $36.67 \pm 6.42$ & 0.854 \\
\hline Simple reaction time (ms) & $338.80 \pm 23.82$ & $346.20 \pm 8.16$ & 0.889 \\
\hline Digit vigilance targets detected (\%) & $98.33 \pm 0.91$ & $97.22 \pm 1.17$ & 0.414 \\
\hline Digit vigilance false alarms (\#) & $2.00 \pm 0.57$ & $1.50 \pm 0.42$ & 0.518 \\
\hline Digit vigilance reaction time (ms) & $467.40 \pm 17.56$ & $491.50 \pm 18.65$ & 0.036 \\
\hline Choice reaction time accuracy (\%) & $97.00 \pm 1.13$ & $96.75 \pm 1.19$ & 0.783 \\
\hline Choice reaction time (ms) & $554.30 \pm 18.68$ & $544.60 \pm 16.07$ & 0.484 \\
\hline Spatial working memory sensitivity index (\#) & $0.97 \pm 0.01$ & $0.96 \pm 0.02$ & 0.786 \\
\hline Spatial working memory reaction time (ms) & $1199.00 \pm 107.00$ & $1084.00 \pm 61.08$ & 0.161 \\
\hline Numeric working memory sensitivity index (\#) & $0.96 \pm 0.02$ & $0.94 \pm 0.04$ & 0.588 \\
\hline Numeric working memory reaction time (ms) & $932.20 \pm 56.28$ & $979.20 \pm 74.50$ & 0.401 \\
\hline Delayed word recall (\% accuracy) & $20.00 \pm 4.36$ & $28.33 \pm 7.43$ & 0.041 \\
\hline $\begin{array}{l}\text { Decay immediate to delayed word recall } \\
\text { (\% accuracy) }\end{array}$ & $16.67 \pm 3.09$ & $8.335 \pm 3.51$ & 0.027 \\
\hline Word recognition sensitivity index (\#) & $0.66 \pm 0.06$ & $0.76 \pm 0.05$ & 0.141 \\
\hline Word recognition reaction time (ms) & $1063.00 \pm 79.5 \mid$ & $1108.00 \pm 77.45$ & 0.484 \\
\hline Picture recognition sensitivity index (\#) & $0.76 \pm 0.05$ & $0.74 \pm 0.06$ & 0.484 \\
\hline Picture recognition reaction time (ms) & $1203.00 \pm 79.83$ & $1254.00 \pm 55.94$ & 0.674 \\
\hline \multicolumn{4}{|l|}{ Cognitive factor } \\
\hline Power of attention & $1360.5 \pm 5 \mid .9$ & $1382.3 \pm 36.2$ & 0.484 \\
\hline Continuity attention & $90.8 \pm 1.0$ & $90.6 \pm 0.8$ & 0.916 \\
\hline Quality of working memory & $1.93 \pm 0.03$ & $1.90 \pm 0.04$ & 0.612 \\
\hline Quality of episodic secondary memory & $189.8 \pm 13.1$ & $205.6 \pm 21.5$ & 0.208 \\
\hline Speed of memory & $4397.3 \pm 270.0$ & $4425.1 \pm 198.6$ & 0.889 \\
\hline
\end{tabular}

Note: The sensitivity index is calculated from formulae presented by Frey and Colliver ${ }^{21}$ and combines the accuracy scores to the original and the novel distracter information.

treatment with PS-omega-3, the immediate word recall capability was generally unaffected; nonetheless, the ability to recall the words after a delay displayed a statistically significant $(P=0.041)$ improvement, which resulted in a significant decrease $(P=0.027)$ in the decay in memory loss from immediate to delayed recall.

No significant effect was obtained for the rest of CDR composite scores; however, a statistically significant $(P=0.036)$ decline in the speed of detections in the vigilance task was observed.

\section{Mood assessment}

None of the mood parameters (alertness, contentment, and calmness) were affected by the treatment (data not shown).

\section{Discussion}

This present pilot study tested the effect of PS-omega-3 consumption on the memory abilities of subjects with subjective memory complaints. The key finding of this exploratory study indicates that PS-omega-3 may have a favorable effect on memory recall in subjects with subjective memory complaints, specifically on the ability to store, hold, and retrieve information of an episodic nature. PS-omega-3 supplementation resulted in a significant increase of $42 \%$ in the ability to recall words in the delayed condition. As immediate word recall for the group remained unchanged over the period, the increase in delayed recall would reflect a decline in the decay of information held in episodic memory.

The study group was well trained on the tasks prior to the study, and thus, we would not expect training effects to be responsible for any changes. Though the trial was not placebo controlled, data from a previously reported clinical study on healthy middle-aged volunteers showed a mean change from baseline score of 3.5 points in delayed recall following 4 weeks treatment in the placebo group, which dropped to 1.9 points at week $8 .{ }^{17}$ This is clearly smaller than the mean change of 8.3 points observed in the present study. Together, this may provide support for the effects being genuine; though, of course, placebo-controlled data are the gold standard.

It is important to note the decline in the speed of detection in the vigilance task; however, this increase in reaction time is hard to interpret, since no other attention parameters were affected. 
The observed benefit of PS-omega-3 on memory is consistent with previous clinical studies in which administration of PS resulted in significant benefits on memory skills in cognitively impaired population following a short supplementation period ${ }^{4}$ and with recent studies which demonstrated the beneficial effects of PS with omega-3 LC-PUFA attached to its backbone. ${ }^{19,20}$ we acknowledge certain limitations in the study design. First, due to the exploratory nature of this study, we chose not to correct for multiple testing; therefore, the study findings should be tested in a confirmatory study. Second, the study sample was small on one hand, and lacking a control group on the other, an issue which again emphasizes the need for a following confirmatory study. Lastly, the inclusion criteria did not determine any prerequisite of a tested memory impairment of the subject, but rather was based on participants' subjective memory complaints.

To conclude, the current exploratory study shows for the first time that consumption of safe source PS-omega-3 might have ameliorating effect on memory capabilities of the elderly population. The results of this pilot trial could assist in planning a future, larger scale placebo-controlled study to evaluate the effect of PS-omega-3 on cognitive impairment in elderly population.

\section{Acknowledgment}

We thank Country Life (Hauppauge, New York, USA) for kindly supplying SharpThought ${ }^{\mathrm{TM}}$, the commercial product of Sharp-PS GOLD.

\section{Disclosure}

This study was funded by Enzymotec Ltd, Israel. Yael Richter, Yael Herzog, and Tzafra Cohen are employees of Enzymotec Ltd.

\section{References}

1. Clark CR, Paul RH, Williams LM, et al. Standardized assessment of cognitive functioning during development and aging using an automated touchscreen battery. Arch Clin Neuropsychol. 2006;21:449-467.

2. Gordon E, Cooper N, Rennie C, Hermens D, Williams LM. Integrative neuroscience: the role of a standardized database. Clin EEG Neurosci. 2005;36:64-75.
Although the results of this pilot study are encouraging,

3. Fünfgeld EW, Nedwidek P. Neurohomologous phosphatidylserine in parkinsonian patients with associated disorders of cerebral metabolism: results of a pilot study. Clin Trials J. 1987;24:42-61.

4. Pepeu G, Pepeu IM, Amaducci L. A review of phosphatidylserine pharmacological and clinical effects. Is phosphatidylserine a drug for the ageing brain? Pharmacol Res. 1996;33:73-80.

5. Vance JE, Steenbergen R. Metabolism and functions of phosphatidylserine. Prog Lipid Res. 2005;44:207-234.

6. Crook TH, Tinklenberg J, Yesavage J, Petrie W, Nunzi MG, Massari DC. Effects of phosphatidylserine in age-associated memory impairment. Neurology. 1991;41:644-649.

7. Cenacchi T, Bertoldin T, Farina C, Fiori MG, Crepaldi G. Cognitive decline in the elderly: a double-blind, placebo-controlled multicenter study on efficacy of phosphatidylserine administration. Aging (Milano). 1993;5:123-133.

8. Amaducci L, Lippi A. Risk factors and genetic background for Alzheimer's disease. Acta Neurol Scand Suppl. 1988;116:13-18.

9. Crook T, Petrie W, Wells C, Massari DC. Effects of phosphatidylserine in Alzheimer's disease. Psychopharmacol Bull. 1992;28:61-66.

10. Calderini G, Aporti F, Bellini F, et al. Pharmacological effect of phosphatidylserine on age-dependent memory dysfunction. Ann N Y Acad Sci. 1985;444:504-506.

11. Vannucchi MG, Pepeu G. Effect of phosphatidylserine on acetylcholine release and content in cortical slices from aging rats. Neurobiol Aging. 1987;8:403-407.

12. Leon A, Benvegnu D, Toffano G, Orlando P, Massari P. Effect of brain cortex phospholipids on adenylate-cyclase activity of mouse brain. J Neurochem. 1978;30:23-26.

13. Argentiero V, Tavolato B. Dopamine (DA) and serotonin metabolic levels in the cerebrospinal fluid (CSF) in Alzheimer's presenile dementia under basic conditions and after stimulation with cerebral cortex phospholipids (BC-PL). J Neurol. 1980;224:53-58.

14. Schreiber S, Kampf-Sherf O, Gorfine M, Kelly D, Oppenheim Y, Lerer B. An open trial of plant-source derived phosphatydilserine for treatment of age-related cognitive decline. Isr J Psychiatry Relat Sci. 2000;37:302-307.

15. Jorissen BL, Brouns F, van Boxtel MP, et al. The influence of soyderived phosphatidylserine on cognition in age-associated memory impairment. Nutr Neurosci. 2001;4:121-134.

16. Wesnes KA, Simpson PM, Christmas L. A microcomputerised system for evaluating the cognitive actions of drugs in the young, elderly and demented. Eur J Clin Pharmacol. 1989;36:38-45.

17. Wesnes KA, Ward T, McGinty A, Petrini O. The memory enhancing effects of a Ginkgo biloba/Panax ginseng combination in healthy middleaged volunteers. Psychopharmacology (Berl). 2000;152:353-361.

18. Bond A, Lader M. The use of analogue scales in rating subjective feelings. Br J Med Psychol. 1974;47:211-218.

19. Vaisman N, Kaysar N, Zaruk-Adasha Y, et al. Correlation between changes in blood fatty acid composition and visual sustained attention performance in children with inattention: effect of dietary n-3 fatty acids containing phospholipids. Am J Clin Nutr. 2008;87:1170-1180.

20. Vaisman N, Pelled D. n-3 phosphatidylserine attenuated scopolamineinduced amnesia in middle-aged rats. Prog Neuropsychopharmacol Biol Psychiatry. 2009;33:952-959.

21. Frey P, Colliver J. Sensitivity and responsivity measures for discrimination learning. Learn Motiv. 1973;4:327-342.

\section{Dovepress}

\section{Publish your work in this journal}

Clinical Interventions in Aging is an international, peer-reviewed journal focusing on evidence-based reports on the value or lack thereof of treatments intended to prevent or delay the onset of maladaptive correlates of aging in human beings. This journal is indexed on PubMed Central, MedLine, the American Chemical Society's 'Chemical Abstracts

Service' (CAS), Scopus and the Elsevier Bibliographic databases. The manuscript management system is completely online and includes a very quick and fair peer-review system, which is all easy to use. Visit $\mathrm{http}: / /$ www.dovepress.com/testimonials.php to read real quotes from published authors. 